\title{
LATITUDINAL GRADIENTS IN \\ LARVAL FEEDING SPECIALIZATION \\ OF THE WORLD PAPILIONIDAE (LEPIDOPTERA)*
}

\author{
By J. Mark Scriber \\ Department of Entomology \\ Cornell University, Ithaca, N. Y. 14850
}

\begin{abstract}
INTRODUCTION
A major question arising from ecological theory is whether or not there are relatively more specialized species in the lower or tropical latitudes than in the higher or more temperate latitudes. There exists a great deal of speculation concerning this question, but little actual data. This article presents an analysis of such data for one family of Lepidoptera; the Papilionidae.

The subject of niche breadth and degree of competitive overlap has generated tremendous interest in the field of ecology in the last two decades. In terms of the spatial model of the niche first proposed by Hutchinson (1957) and later expanded by Slobodkin (1962), Levins (1968), and MacArthur (1968), niche breadth is the "distance through" a niche hypervolume along a particular resource gradient within a community (Colwell and Futuyma, I97I ; Whittaker, et al., 1973).

Although there is presumed to be an apparent limit to the similarity and hence the number of competing species that can coexist (MacArthur and Levins, 1967), the packing of species (MacArthur, I969a) appears to be roughly proportional to the environmental variance, with less overlap, or looser packing, occurring with increased environmental fluctuation or perturbation. May and MacArthur (1972) imply that niche overlap may be relatively independent of small to moderate environmental fluctuations, but it remains true that greater packing could still be attained by specialization, and the question concerning what ultimately limits niche width remains unsettled. Also, in a more stable environment of the tropical latitudes, with larger productivity one might expect that marginally scarce resources would become adequate to support new species at the extremes of the resource gradient (Odum, et al., I960; Connell and Orias, 1964). In a more stable low-latitude tropical environment (MacArthur, 1969a), old lakes (Kozhov, 1963), the
\end{abstract}

*Manuscript received by the editor October 18, 1973 
benthos (Sanders, 1968, 1969) or coral reefs (Kohn, 1968) we expect closer packing and greater numbers of competitors per community (Levins, 1968; MacArthur and Levins, 1967; Vandermeer, 1970) with narrower realized niches and increased ecological differentiation and niche specificity (Whittaker, et al., I954; Klopfer, 1959; Selander, I965; Millar, 1969).

Although species diversity varies from one community to the next, it is often greatest in the lower latitudes. Sanders ( 1969) incorporates many of the earlier proposed explanations of differences in species diversity (Pianka, I966; Paine, 1966; Connell and Orias, 1964; MacArthur, 1965, I969b) in his stability-time hypothesis. According to this hypothesis, the greater number of species in the tropics implies a greater number of biotic interactions than in the temperate regions. The results of competition would be most obvious in the form of niche divergence and increased specializations over a resource gradient. The corresponding decrease in predictability and stability of environmental conditions with an increase in latitude may mean that species in temperate regions are influenced more by the physical environment than by competitive interactions (Slobodkin and Sanders, 1969; Janzen, 1970). Realized niches may be smaller in the tropical or low latitudes than in higher latitudes because of the expected difficulties of specializing in an unpredictable environment and of generalizing in an extremely diverse and competitive environment. The following investigation was undertaken in an attempt to determine the correctness of the premise that realized feeding niches are relatively more specialized in the tropical and subtropical latitudes than in the higher latitudes.

\section{METHODS}

My approach was to choose a single taxonomic group that is cosmopolitan, whose habits are relatively well known and which all nicely fall into a single 'guild' (Root, 1967). The 538 species of Papilionidae (Lepidoptera) of the world, based on Munroe's classification, met these criteria adequately.

In order to analyze a niche breadth it was necessary to choose a criterion that could be compared over a range of latitudes and not one that varied between communities. Therfore, I investigated larval host plant relationships arbitrarily designating those species feeding on more than one taxonomic family of plants as "generalists," or wide-niched, species. By using food-plant range as such, latitudinal comparisons of food-plant specialization, or trophic niche breadth 


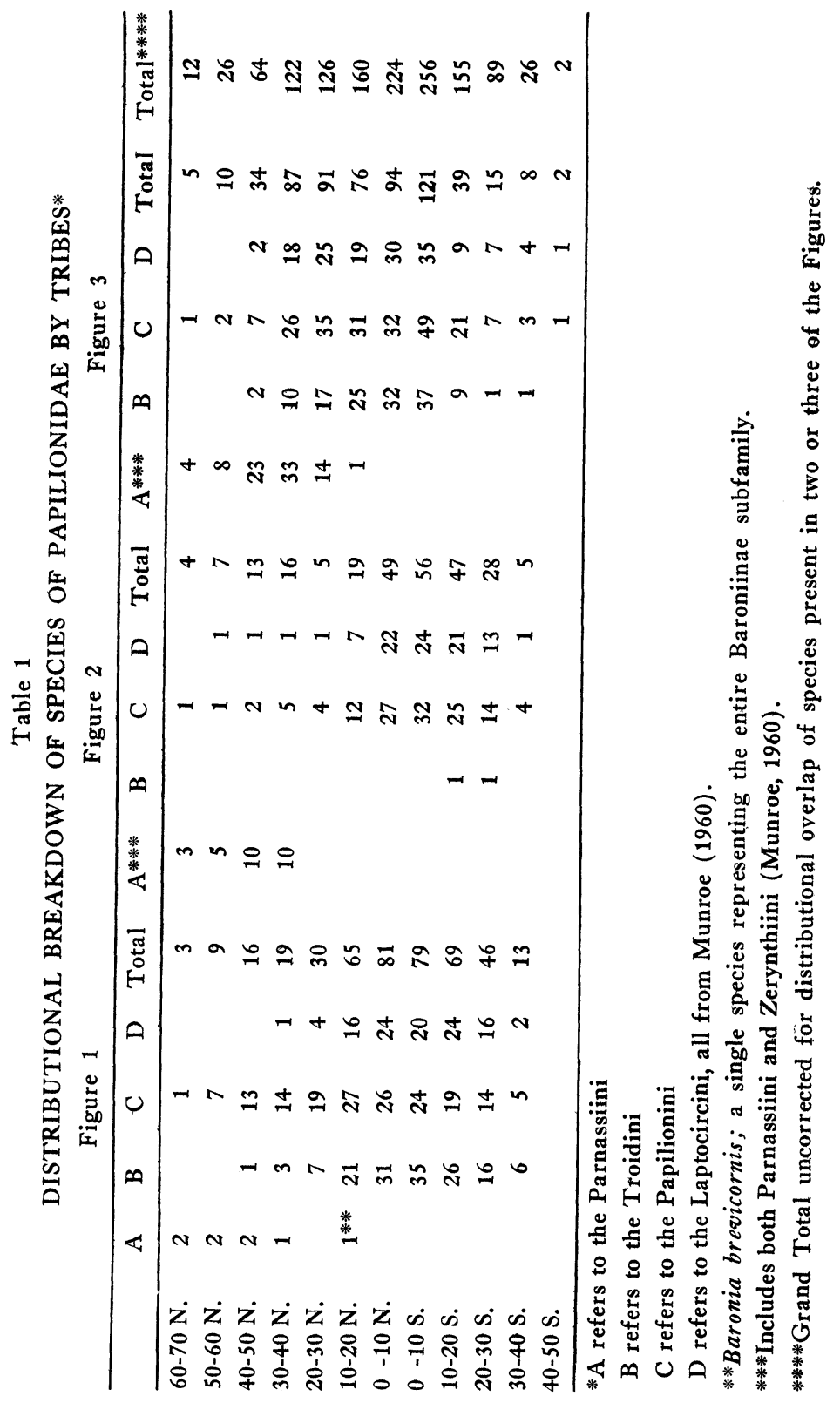




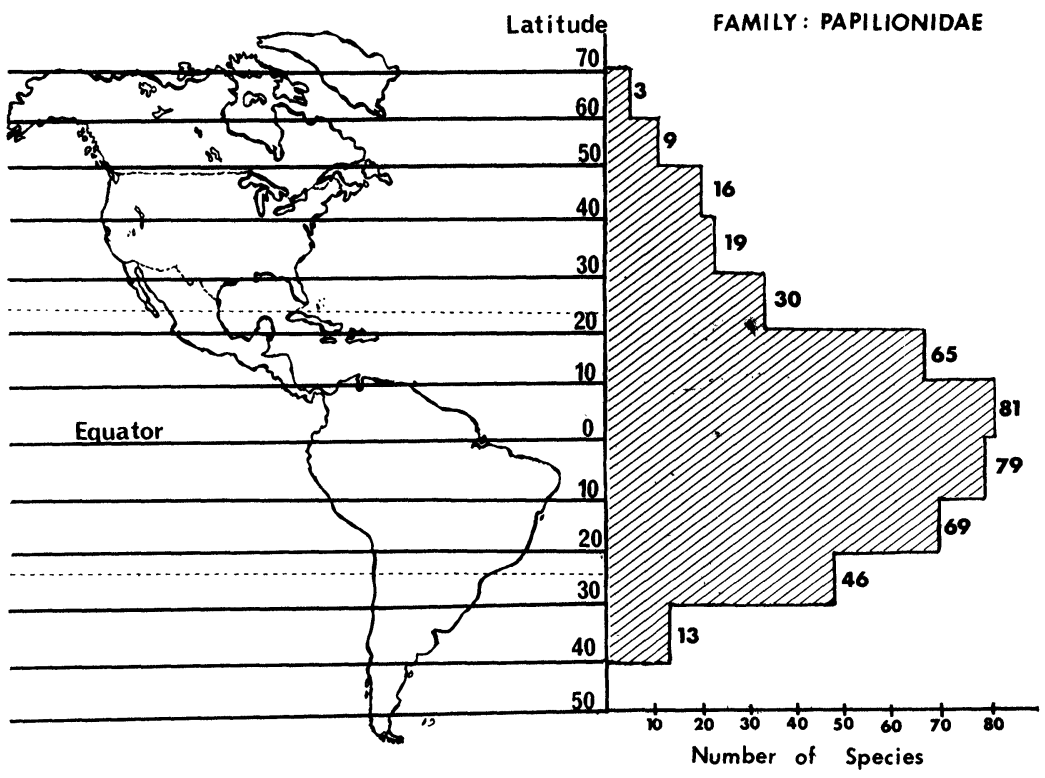

Fig. 1. Latitudinal gradients in species richness for the New World Papilionidae (Modified from Slansky, 1972)

were simplified considerably. As explained in the discussion, it was not desired to use degree of morphological correlation with feeding specialization as an index of niche breadth.

Because larvae generally remain upon the host plant throughout most of their existence, the food-plant is especially likely to be the key factor in the niche of most butterfly species since, to a large extent, it is also the shelter, substrate, or habitat upon which allelochemical co-evolution (Ehrlich and Raven, 1965; Whittaker and Feeny, 197I) of the entire 'component community' (Root, 1973) takes place. In this sense it is essentially difficult to differentiate between 'niche' and 'habitat' (Whittaker, Levin, and Root, I973), and their term 'ecotope' might be more appropriate since it entails the inter-community as well as the intra-community variables.

I have compiled range maps of each of the 538 species of Papilionidae of the world (Munroe, 1960) using the techniques of Slansky (1972). I used Goode's Atlas (Espenshade, I960) and locality data recorded in the literature, primarily in Rothschild (1895), Rothschild and Jordan (1906), Aurivillus (1908-1910), 
Bollow (1929), Fruhstorfer (1908), Jordan (1907, 1908-1909), von Rosen (1929), Seitz (1906), Stichel (1906), Shirozu (1960), D'Almeida (1966), and Common and Waterhouse (1972).

The number of species known to occur in each ten degree latitude belt was recorded. The worldwide data were divided into the three geographical sections in figures $\mathrm{I}, 2$, and 3 to simplify the analysis. The components of each of these figures are shown in tabular form (Table I).

The species of known larval food-plants were compiled from the literature, although care was used in interpreting recorded host plant records (see Ehrlich and Raven, 1965; and Shields, Emmel, and Breedlove, 1969). The plant classification follows Willis (1973). A supplementary table with each species of Papilionidae with its latitudinal range, food-plant families fed upon, and citations for these food plant records is available from the author and at the following libraries: Cornell University (Entomology), Harvard (M.C.Z.), and the U.S.N.M. ${ }^{1}$

With those species feeding on more than one taxonomic family of plants as my "generalists" or wide-niche species, a species was counted in all parts of its range as being a wide-niche species, or generalist, if it feeds on more than one plant family anywhere in its range.

Latitudinal gradients in niche breadth were prepared by enumerating the species for each ten degree belt of latitude and calculating the percentage of species exhibiting a "general" feeding strategy.

Although the foodplants of the Papilionidae are probably as well known as those of any other taxon of similar magnitude, there are still gaps in the record. In the case of a species of unknown foodplant preference I have assumed that the host plant family range utilized is, in general, similar to those of closely related species of the group. There are, for example, many tropical Troidini for which the precise species of Aristolochia utilized are not known.

Longitudinal and altitudinal variations in species richness are an important and interesting part of distributional patterns, but were: not considered in this study.

\section{RESULTS}

Species richness is greatest in the tropical latitudes for each of thethree geographical regions (Figures I, 2, 3). The significance of this trend for Papilionidae in the New World is discussed by Slansky

\footnotetext{
${ }^{1}$ The Grace Griswold Fund of the Department of Entomology of Cornell University assisted with the expense of having the supplementary tables of data copied.
} 

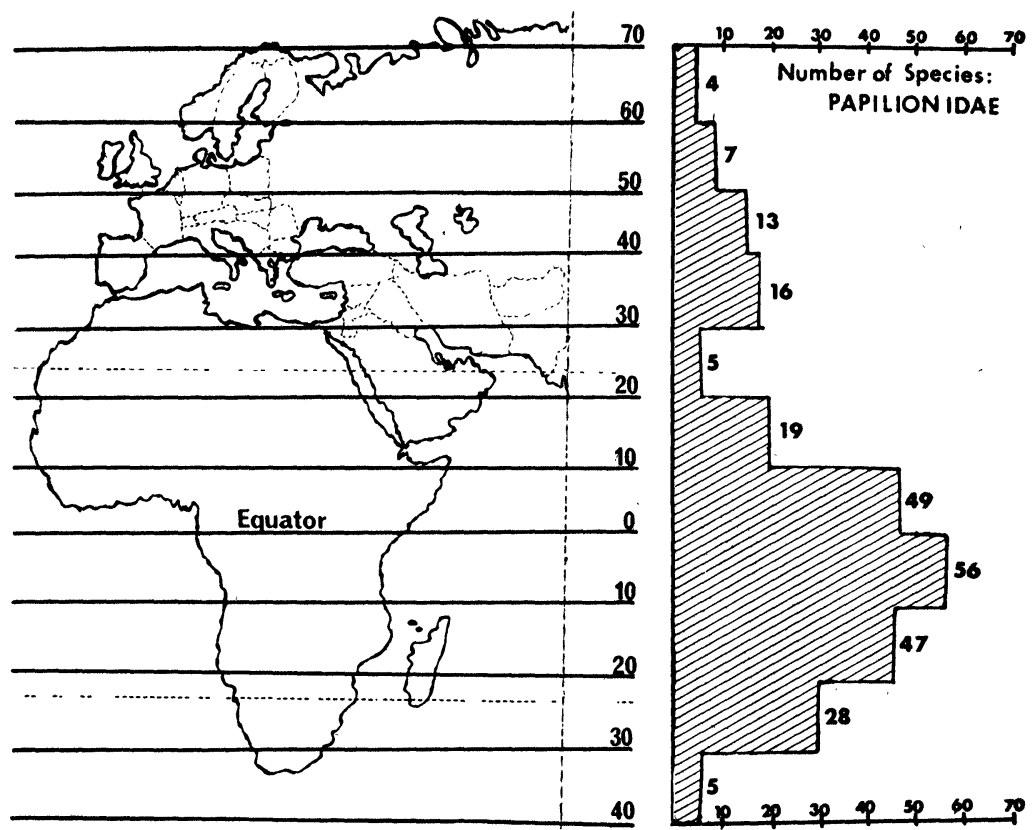

Fig. 2. Latitudinal gradients in species richness for Eurasian and African Papilionidae.

(1973). The smaller number of species of Papilionidae occurring in the 20-30 degree North latitude belt of figure 2 is presumably due to the Sahara and Arabian deserts. The great number of species in the 20-40 degree North latitude belts in figure 3 is correlated to a large degree with the strong radiation especially of the Parnassiinae and also of the Papilioninae subfamilies in the mountainous Himalaya region and the Tibetan Plateau. (See Table I.) There is a relatively sudden drop in species richness south of io degrees South latitude in figure 3, the biogeographical relevance of which is uncertain.

Figure 4 shows the overall pattern of latitudinal gradients in the number of species of Papilionidae, corrected for distributional overlap of certain species that occurred in more than one of the earlier three figures. Also the number of species for each tribe of Papilionidae feeding on two or more plant families and the overall percentage of generalized feeders for each latitudinal belt are shown in relation 
to this pattern. Note that there is a considerable decrease in the percentage of generalists toward the lower tropical latitudes (Figure 5).

\section{Discussion}

Although the absolute number of generalists is not strikingly different, it is readily apparent that the percentages are considerably less in the lower latitudes. This fact appears to support the premise that there are relatively fewer generalists in the tropics and relatively more in the higher latitudes. There is, however, no sharp division, but instead a gradient of increasing relative degree of specialization from the extremes of latitude to the equatorial regions. It is not known whether increased competition could be the cause or the result of the increasing diversity gradients toward the lower latitudes, nor is it certain whether the observed gradients in feeding niche breadth are due to ecological release from competition in higher latitudes or just the inability to specialize in their unpredictable and unstable environmental conditions.

It was assumed throughout this study that the niche breadth as measured here is that of the 'realized' niche as opposed to the 'fundamental' (Odum, 197I). This study of feeding niche breadths involves a cross section of both 'evolutionary' and 'ecological' time (Slobodkin, 1962) and the differentiation at both intra- and interpopulation levels. That is, there are probably areas of active competition where we are not viewing only the neat results of evolutionary processes that have already and permanently narrowed the realized hostplant ranges from those plant families which are physiologically exploitable, but there are also the currently unfolding consequences of ecological interactions that someday may or may not result in more specialized herbivores. It should be noted that the relative merits of either specializing or generalizing may involve 'qualitative' and 'quantitative' chemical defense of the host plants (Feeny, 1974) as well as other ecological factors besides competition alone.

Emmel and Emmel (1969) have shown that for Papilio indra (Reakirt) and Papilio rudkini (Comstock) direct competition of sympatric populations is avoided most of the time by temporal isolation and utilization of mutually exclusive food-plant families. In one instance however they found that food did become the limiting resource and the separate host preferences broke down when the favored food became scarce. In this situation both Umbelliferae and Rutaceae were then utilized by the insects of these populations. Further evidence that competitive interactions leading to adaptations 


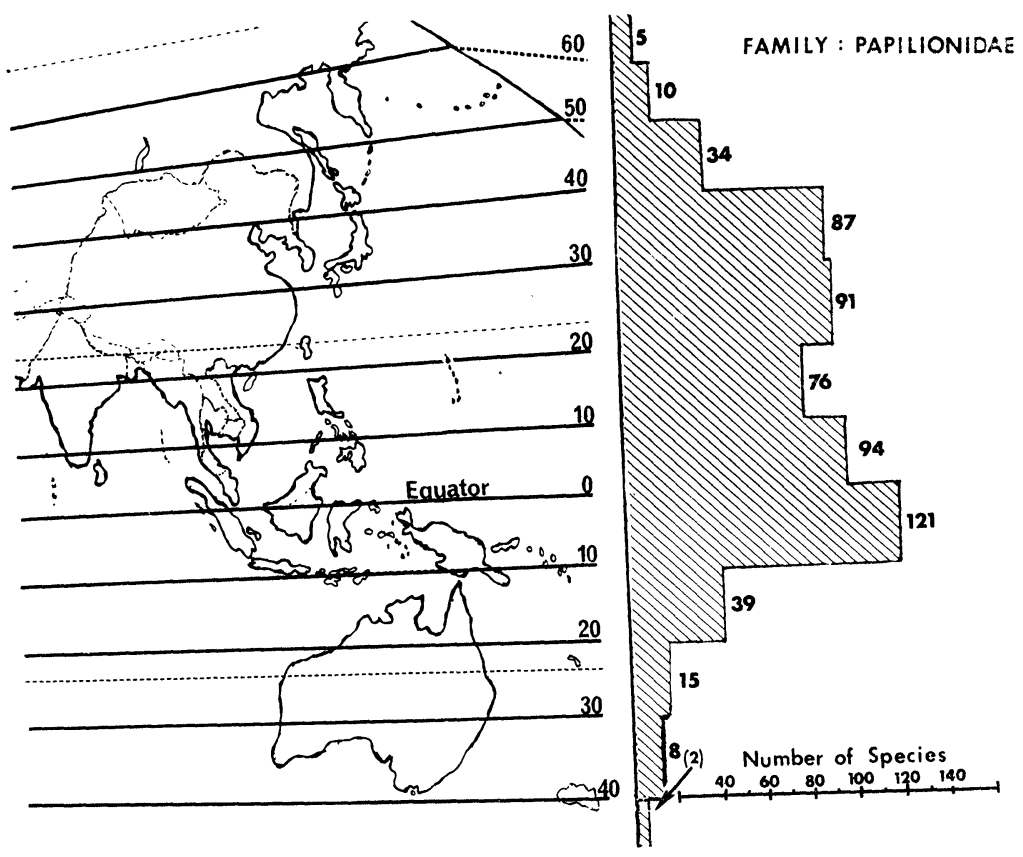

Fig. 3. Latitudinal gradients in species richness for Indo-Australian and Eastern Asian Papilionidae.

that permit the coexistence of several species of butterflies should probably be sought in the larval rather than the adult stages has been obtained by Young (1972). The critical dimension of the niche (or ecotope) may in fact be something other than the range of larval hostplants utilized; however, as well as being one that is relatively easy to measure, it is assumed here to be a crucial parameter in most cases.

In a relatively recently speciated group of swallowtails in the U.S., the polyphagous Papilio glaucus (L.) is apparently entirely excluded geographically by three species which are sympatric and which have subdivided the range of plant families utilized by $P$. glaucus (Brower, 1958a; 1959). Besides their specialized feeding habits, isolating mechanisms such as seasonality, coloration, and mating preferences appear to have been involved in the Pleistocene speciation. There is no clear cut distinction between ecological and evolutionary time, and the importance of trophic specialization is uncertain 
in this and similar cases such as the four species of the $P$. demodocus (Esper) group of swallowtails that have evolved on Madagascar, or the three species of the P. nireus (L.) group in West Africa that are presumed to have speciated during the Tertiary when the climate and vegetation were rapidly changing (Owen, I97 I). Furthermore, because the author is in this study to a large degree uncertain of regional food plant preferences that might distinguish a polymorphic population of specialized individuals from a monomorphic population of generalized individuals, no attempt has been made to differentiate any components of niche breadth as described by Roughgarden (1972).

It is probably fair to assume that neither the latitudinal gradients in diversity nor those for trophic niche breadth remain constant for any long periods of time. The phylogenetic histories of the Papilionidae are certainly intertwined with the zoogeographical movement and changes in the flora of major continents (Hovanitz, 1958; Carcasson, 1964; and Kostrowicki, 1969), and this paper is merely an attempt to look at the present state of these continually changing phylogenies.

Besides regional preferences there can be temporal changes in foodplant preferences and these are frequently accentuated by human agriculture. Owen (I97I) points out that several species of African papilionids have recently expanded their ranges and seasonal abundance by switching from their wild Rutaceous foodplants onto cultivated varieties of Citrus which, unlike the wild plants, maintain their leaves throughout the dry season and are spreading rapidly with agricultural development. The extent to which members of the Papilionidae have become secondarily polyphagous on completely new plant families or else by revitalized usage upon re-exposure to ancestral hostplant families is uncertain. It is very likely that besides the general ecological pressures such as competition with more specialized herbivores, there may well be both 'fixed' and 'variable' metabolic 'cost' associated with any extension of the normal range of food plants utilized by a species (Feeny, 1974). In Papilio demoleus for example the principal natural foodplants for Papilio demoleus stheneles (Macleay) in Australia are Psoralea tenax and P. patens which are members of the Leguminosae family (D'Abrera, I97I; McCubbin, 197I; and Common and Waterhouse, 1972), while in Ceylon and India the presumed ancestral $P$. demoleus demoleus (L.) feed primarily upon various Rutaceae, such as Aegle, Clausenia, Glycosmis, and Citrus (Woodhouse, I950; and Igarashi, I966). Although the females of $P . d$. stheneles oviposit upon Citrus in Queens- 
Number of Generalized

feeders *

Number of Species Latifude World Papilionidae

A B C D total Generalized

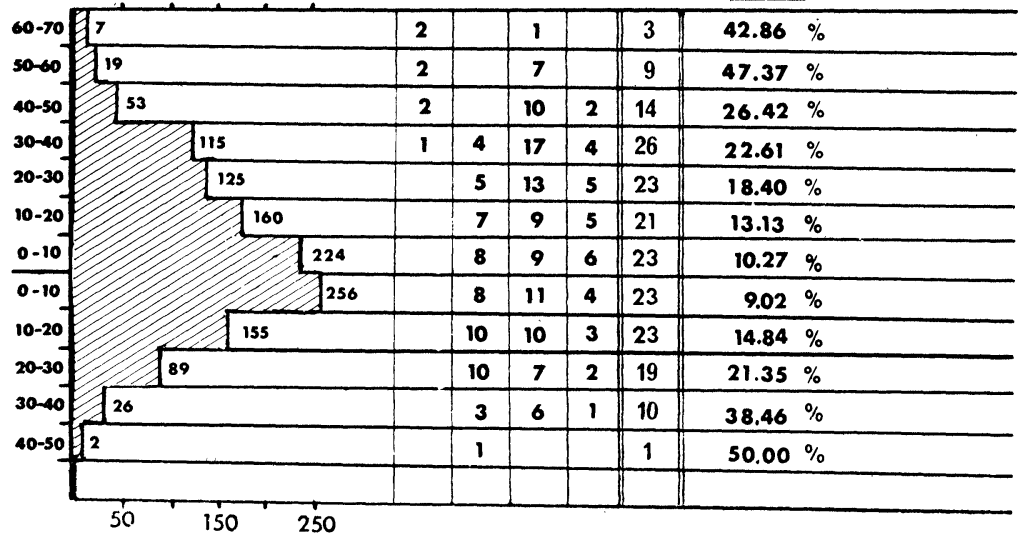

Fig. 4. Latitudinal gradients in species richness and percentage of generalized species of Papilionidae of the world. $A=$ Parnassini; $B=$ Leptocircini; $\mathrm{C}=$ Papilionini $; \mathrm{D}=$ Troidini.

land (Australia), the larvae are unsuccessful and eventually die when left to feed upon leaves of this relatively recent introduction (Edwards, 1948; and Straatman, 1962). It appears thus that in at least some populations metabolic specializations or adjustments may have coevolved along with the regional restriction in food-plant choice such that Citrus is perhaps in some way no longer physiologically suitable for those individuals. It should be pointed out that individuals from some Australian populations can and do successfully utilize the native rutaceous Microcitrus australis (D'abrera, I97I), and those in New South Wales can be reared successfully upon Citrus (see Straatman, 1962).

It is interesting that in Africa Papilio demodocus (Esper), a species which is very closely related to and once considered a race of $P$. demoleus, is primarily a Rutaceae-feeder over most of its range. It is however polymorphic (Clarke, et al. 1963) and also utilizes the Umbelliferae in South Africa where the richness of this plant family is relatively high (Dethier, I94I). Similarly, the P. machaon group of Umbellifer feeding species in Sardinia, East Asia, and North America are also close to $P$. demoleus in ancestry (Munroe, 1960). 
Further speciation has apparently taken place in those regions where Umbelliferae are most diverse. Several of these species, however, are still able to utilize rutaceous foodplants.

Feeding patterns of the Papilionidae and phytophagous insects in general, range from strict monophagy (stenophagy), in which a single species of foodplant is utilized, to wide polyphagy (euryphagy) in which many species, genera, or families may be utilized (Brues, I920; Dethier, 1954). The exploitation of a particular hostplant involves many adjustments on the part of the insect to the plant's microcommunity. This includes host-specific predators (Brower, 1958b) and parasites (Read et al., 1970). Facultative polyphagy in some Papilio larvae, conveying the ability to take advantage of ovipositional mistakes of the adult, may allow some escape from the intense mortality rates that can result from host-specific parasitism (Stride and Straatman, 1962). Polymorphisms in larval color patterns can also be involved (Clarke et al., 1963), but perhaps the most important factor in this coevolving community is the metabolic adjustments on the part of the insect to the secondary chemistry of the plant (Fraenkel, 1959; Jermy, 1966; and Thorsteinson, 1960). As pointed out by Ehrlich and Raven (1965), the plasticity of the chemoreceptive response and the potential for physiological adjustments to secondary plant chemicals may be very important factors in determining the potential for evolutionary radiation in a phytophagous species. Since the possibility exists that taxonomically generalized feeders may in fact be allelochemical specialists that cue in on one key set of chemicals in the plants, feeding niche breadth may well take on new meaning.

Increased specialization by a species is generally presumed to increase the competitive ability of a species largely because the species utilizes its resources more efficiently (Emlin, 1966; MacArthur and Levins, 1964; MacArthur and Pianka, 1966; Morse, 1971 ; Rosenzweig, 1966; and Schoener, 197I). Presumably, the less efficient species should be completely eliminated (MacArthur, 1972) or crowded to the periphery to become a specialist on another niche dimension (McNaughton and Wolf, I970). In this sense, the relative efficiencies of exploiting a critical limiting resource may in large part determine the niche breadth.

Previous attempts to measure niche breadths have had varying degrees of success. Various works in the literature attempt to relate morphological characters, behavioral repertoires or habitat selection response with niche breadth or overlap (Klopfer, 1962, I967; Schoener, 1969; Van Valen, I965; and Wellington, I968). Upon 


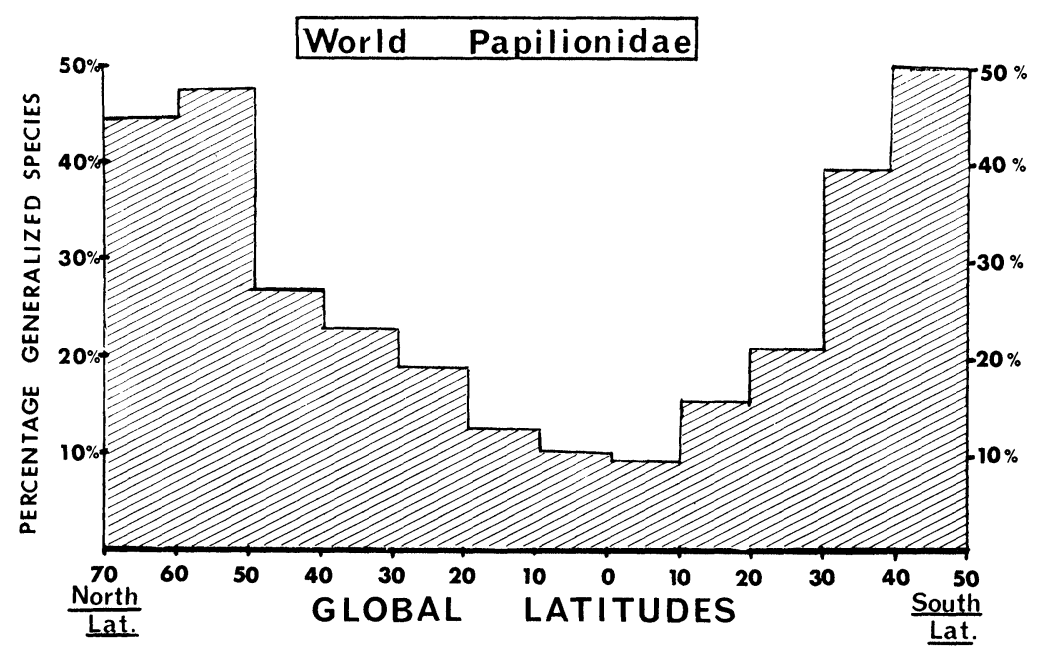

Fig. 5. Latitudinal gradients in feeding specialization for the Papilionidae of the world.

ecological release from competition upon islands (MacArthur and Wilson, 1967), various workers have found some evidence that species niches do appear to broaden in the sense that there is increased morphological variance, behavioral plasticity, and dominance (Grant, 1967 ; Lack and Southern, 1949; Patrick, 1967; Vaurie, 1957; Williams, I969; and Wilson, I96I). There is, however, some question whether these measures actually reflect niche breadth of the species (Soule and Stewart, 1970; Willson, 1969). I have employed a somewhat different measure here, and by altering the number of families or genera used as a criterion for 'generalist', the amplitude of the observed latitudinal gradient would vary but probably not the overall pattern. Other studies have described a 'generalist' in somewhat different terms as those species able to maintain populations over a broad range of environmental types or substrates (McNaughton and Wolf, 1972), or those exhibiting a greater variance or breadth of morphology or feeding behavior (Levins, 1968; Roughgarten, 1972; Schoener, 1971). These also may or may not reflect actual niche breadth as such, but latitudinal comparisons within a taxocene would probably be possible to prepare in these terms as well.

It is interesting that many species of Papilionidae are relatively specialized on certain tropical and sub-tropical plant families (Slan- 
sky, 1972). In the higher latitudes where fewer species of most major families of host plants occur there has probably been some breakdown of the phylogenetic larval host plant preferences that tie some species to these major evolutionary host plant groups, perhaps favoring polyphagy at the plant family level. The Papilio troilus L. and P. glaucus L. groups, for instance, have expanded their diets considerably from the Lauraceae and Magnoliaceae they are thought to have originally fed upon. Thus, besides 'ecological release' and the inability to specialize in unpredictable and unstable environments as possible explanations of the observed gradients in feeding specialization, a third possibility exists. Perhaps there was a necessary alteration of those allelochemical specializations developed over a long period of evolutionary time, either as species of Papilionidae extended their ranges into the higher latitudes where their usual host plant families never existed, or as they remained in higher latitudes where their ancestral hosts had since been eliminated, perhaps by climatic changes.

The precise reason for Papilionidae being more specialized in their feeding habits in tropical latitudes is uncertain and will probably remain largely as such. One contributing factor for this is that no one knows whether polyphagy in general is the ancestral condition from which more specialized feeding habits arose or not. The fact exists, however, that there are greater percentages of feeding specialists in the tropical latitudes, and that this percentage decreases as one moves toward the higher latitudes. These data do not suggest that species are more specialized in the tropical than temperate latitudes, but that more species are specialized.

\section{SUMMARY}

Latitudinal gradients in food plant specialization are examined for the swallowtail butterflies of the world (Papilionidae). It is found that the absolute number of generalized feeders existing in each ten degree belt of latitude is fairly constant, but the relative percentage of generalized species is significantly higher in the higher latitudes. This fact is discussed in terms of trophic niche breadth and species diversity of the Papilionidae in tropical and temperate regions.

\section{ACKNOWLEDGEMENTS}

This work was supported by N.S.F. Grant \#GB 33398 (P.P.F.). I wish to thank Drs. Paul Feeny, J. G. Franclemont, Robert Poole, and Frank Slansky, Jr. for reading the manuscript or supple- 
ment and offering instructive criticisms. Special thanks are extended to Frank Slansky, Jr. for helpful data concerning certain Papilionidae, to J. G. Franclemont for generous amounts of his time and assistance, and to Kathleen Scriber for assistance in the preparation of parts of the manuscript and supplement.

\section{Literature Cited}

Aurivillius, C.

1908-10. Papilio. In (A. Seitz ed.) The Macrolepidoptera of the world. The African Rhopalocera. Alfred Kernen. Stuttgart. 13: 11-28.

Bollow, C.

1929. Parnassius. In (A. Seitz ed.) The Macrolepidoptera of the World. The Palearctic Butterflies. Alfred Kernan. Stuttgart.

BRower, L. P. Suppl. $1: 20-83$.

1958a. Larval foodplant specificity in butterflies of the Papilio glaucus group. Lepid. News 12: 103-114.

1958b. Bird predation and foodplant specificity in closely related Procryptic insects. Amer. Nat. $92:$ 183-187.

1959. Speciation in butterflies of the Papilio glaucus group. Parts I and II. Evol. $13: 40-63$; 212-228.

BRUES, C. $T$.

1920. The selection of foodplants by insects with special reference to Lepidopterous larvae. Amer. Nat. 54: 313-332.

Carcasson, R. H.

1964. A preliminary survey of the zoogeography of African butterflies. E. Afr. Wildlife J. 2: 122-157.

Clarke, C. A., C. G. C. Dickenson, and P. M. Sheppard.

1963. Larval color pattern in Papilio demodocus. Evol. 17: 130-137.

Colwell, R. K. and D. J. Futuyma.

1971. On the measurement of niche breadth and overlap. Ecology 52: 567-576.

Common, I. S. B. And D. F. Waterhouse.

1972. Butterflies of Australia. Angus and Robertson Ltd., Brisbane. $498 \mathrm{p}$.

Connell, J. H. and E. Orias.

1964. The ecological regulation of species diversity. Amer. Nat. 98: 399-414.

D'ABRERA, B.

1971. Butterflies of the Australian region. Lansdown Press. Melbourne. $415 \mathrm{p}$.

D'Almeida, R. F.

1966. Catalogo dos Papilionidae Americanos. Sociedade Brazileiro Entomologica. Sao Paulo, Brazil. 366 p.

Dethier, V. G.

1940. Life histories of Cuban Lepidoptera. Psyche 47: 14-26.

1941. Chemical factors in determining the choice of foodplants by Papilio larvae. Amer. Nat. $75:$ 61-73. 
1954. Evolution of feeding preferences in phytophagous insects. Evol. 8: 33-34.

Ehrlich, P. R. And P. H. Raven.

1965. Butterflies and plants: a study in coevolution. Evol. 18: 586-608. EMLIN, J. M.

1966. The role of time and energy in food preferences. Amer. Nat. 100: 611-617.

EMmel, T. C. AND J. F. EMmel.

1969. Selection and host plant overlap in two desert Papilio butterflies.

FEENY, P. P. Ecology 50: 158-159.

1974. Biochemical coevolution between plants and their insect herbivores. In Coevolution of Animals and Plants (L. E. Gilbert and P. H. Raven eds.) Symp. 1st Int. Congr. Syst. \& Evol. Biol. Boulder, Colorado (August, 1973). Univ. Texas Press, Austin (in press).

FraEnKeL, G.

1959. The raison d'etre of secondary plant substances. Science 129: 1466-1470.

Fruhstorter, $\mathrm{H}$.

1908. Parnassius. In (A. Seitz ed.) The Macrolepidoptera of the World. The Indo-Australian Rhopalocera. Alfred Kernen. Stuttgart. 9 : 109-112.

Goope, J. P.

1960. World Atlas. Espenshade, E. B. (ed.). Rand McNally Co., Chicago. 288 p.

GranT, P. R.

1967. Bill length variability in birds of the Tres Marias Islands, Mexico. Can. J. Zool. 45 : 805-815.

Hovanitz, W.

1958. Distribution of butterflies in the new world. In (C. L. Hubbs ed.) Zoogeography. (p. 321-368). Amer. Assoc. Adv. Sci. Publ. 51.

IGARASHI, S.

1966. Butterflies of Nepal; Immature Stages. Special Bull. Lep. Soc. Japan (no. 2) 1-74.

JANZEN, D. H.

1970. Herbivores and the number of tree species in tropical forests. Amer. Nat. 104: 501-528.

JERMY, T.

1966. Feeding inhibitors and food preferences in chewing phytophagous insects. Ent. Exp. et Appl. 9: 1-12.

JORDAN, K.

1907. Papilio. In (A. Seitz ed.) The Macrolepidoptera of the World. The American Rhopalocera. Alfred Kernen. Stuttgart. 5: 11-45. 1908-09. Papilionidae. In (A. Seitz ed.) The Macrolepidoptera of the World. The Indo-Australian Rhopalocera. Alfred Kernan. Stuttgart. 9: 11-109.

KLOPFER, P. H.

1959. Environmental determinants of faunal diversity. Amer. Nat. 93 : 337-342. 
1962. Behavioral aspects of Ecology. Prentice Hall. Englewood Cliffs, New Jersey. $161 \mathrm{p}$.

1967. Behavioral stereotypes in birds. Wilson Bull. 79: 290-300.

Klopfer, P. H. And R. H. MacArthur.

1960. Niche size and faunal diversity. Amer. Nat. 94: 293-300.

1961. On the causes of tropical species diversity: niche overlap. Amer. Nat. $95: 223-226$.

KoHn, A. J.

1968. Microhabitats, abundance and food of Conus on atoll reefs in the Maldive and Chagos Islands. Ecolgy 49: 1046-1061.

Kostrowicki, A. S.

1969. Geography of the Palearctic Papilionidae (Lepidoptera). Panstwowe Wydawnictwo Naukowe, Poland. 380 p.

Kozноv, M.

1963. Lake Baikal and its life. W. Junk Publ. The Hague. 344 p.

LACK, D. and H. N. Southern.

1949. Bird's on Tenerife. Ibis $91:$ 607-626.

Levins, $R$.

1968. Evolution in changing environments. Princeton Univ. Press. Princeton, N.J. $120 \mathrm{p}$.

MacArthur, R. H.

1965. Patterns in species diversity. Biol. Rev. 40: 510-533.

1968. The theory of the niche. In R. C. Lewontin (ed.). Population Biology and Evolution. Syracuse Univ. Press, Syracuse, N.Y.

1969a. Species packing, or what competition minimizes. Proc. Nat'n. Acad. Sci., U.S. 64 : 1369-1371.

1969b. Patterns of communities in the tropics. Biol. J. Linn. Soc. 1: 19-30.

MacArthur, R. H. And R. Levins.

1964. Competition, habitat selection, and character displacement in a patchy environment. Proc. Nat. Acad. Sci. U.S. 51: 1207-1210.

1967. The limiting similarity convergence, and divergence of coexisting species. Amer. Nat. 101:377-385.

MacArthur, R. H. and E. R. Pianka.

1966. On optimal use of a patchy environment. Amer. Nat. 100: 603-604.

MacArthur, R. H. and E. O. Wilson.

1967. The theory of island biogeography. Princeton Univ. Press. Princeton, N.J. 203 p.

May, R. M. and R. H. MacArthur.

1972. Niche overlap as a function of environmental variability. Proc. Nat. Acad. Sci. U.S. 69: 1109-1113.

McNaughton, S. J. AND L.L. Wolf.

1970. Dominance and the niche in ecological systems. Science 67: 131-139.

Millar, R. S.

1969. Competition and species diversity. In Diversity and stability in ecological systems. Brookhaven Symp. Biol. 22: 63-70.

MoRse, D. H.

1971. The insectivorous bird as an adaptive strategy. Ann. Rev. Ecol. and Syst. $2: 177-200$. 
Munroe, E.

1960. The classification of the Papilionidae (Lepidoptera). Can. Ent. suppl. $17: 1-51$.

Odum, E. P.

1971. Fundamentals of Ecology. 3rd Edition. W. B. Saunders Co. Philadelphia. $574 \mathrm{p}$.

Odum, H. T., J. Cantlon, and L. S. Kornicker.

1960. An organizational hierarchy postulate. Ecol. 41: 395-399.

OWEN, D. F.

1971. Tropical butterflies. Clarendon Press, Oxford. 214 p.

P.Aine, R. T.

1966. Food web complexity and species diversity. Amer. Nat. 100: 65-75.

Patrick, $R$.

1967. The effect of invasion rate, species pool, and size of area on the structure of the diatom flora. Proc. Nat. Acad. Sci. U.S. 58 : 1335-1342.

Pianka, E. C.

1966. Latitudinal gradients in species diversity: a review of the concepts. Amer. Nat. 100 : 33-46.

Read, D. P., P. P. Feeny and R. B. Root.

1970. Habitat selection by the aphid parasite Diaeretiella rapae ( Hymenoptera: Braconidae) and hyperparasite Charips brassicae (Hymenoptera: Cynipidae). Canad. Ent. 102: 1567-1578.

Root, R. B.

1967. The niche exploitation pattern of the blue-gray gnat catcher. Ecol. Monogr. 37 : 317-350.

1973. Organization of a plant-arthropod association in simple and diverse habitats: the fauna of collards (Brassica oleracea). Ecol. Monogr. 43 : 95-124.

von Rosen, K.

1929. Papilio. In (A. Seitz ed.) The Macrolepidoptera of the World. The Palearctic Butterflies. Alfred Kernen. Stuttgart. Suppl. 1: 7-20.

Rosenzweig, M. L.

1966. Community structure in sympatric carnivora. J. Mammal. 47: 602-612.

RothschiLD, W.

1895. A revision of the Papilios of the Eastern hemisphere, exclusive of Africa. Novitates Zoologicae Vol. II. Hazell, Watson and Viney. London. 167-463.

ROTHSCHILD, W. AND K. JORDAN.

1906. A revision of the American Papilios. Novitates Zoologicae 8. Hazell, Watson and Viney. London. 411-753.

Roughgarden, J.

1972. Evolution of niche width. Amer. Nat. 106: 683-718.

SANDERS, H. L.

1968. Marine benthic diversity: a comparative study. Amer. Nat. 102: 243-282.

1969. Benthic marine diversity and the stability-time hypothesis pp. 7181. In Diversity and stability in ecological systems. Brookhaven Symposium in Biology 22. 
SCHOENER, T. W.

1969. Madels of optimal size for solitary predators. Amer. Nat. 103: 277-313.

1971. Theory of feeding strategies. Ann. Rev. Ecol. and Syst. 2: 369-404.

SCRIBER, J. M.

1972. Confirmation of a disputed foodplant of Papilio glaucus. J. Lepid. Soc. 26 : 235-236.

SCUDDER, S. H.

1889. The butterflies of the eastern United States and Canada. S. H. Scudder. Cambridge. Vol. 2.

SeITZ, A.

1906. Papilio. In (A. Seitz ed.) The macrolepidoptera of the world. The palearctic butterflies. Alfred Kernen. Stuttgart. 1: 7-18.

SELANDER, R. K.

1965. Sexual dimorphism and differential niche utilization in birds. Condor 68: 113-151.

Shields, O., J. F. Emmel and D. E. Breedlove.

1969. Butterfly larval foodplant records and a procedure for reporting foodplants. J. Res. Lepid. $8: 21-36$.

SHIROZU, T.

1960. Butterflies of Formosa in Colour. Hoikusha, Osaka. 481 p.

Slansky, F.

1972. Latitudinal gradients in species diversity of the New World swallowtail butterflies. J. Res. Lepid. 11(4) : 201-218.

SLOBODKIN, L. B.

1962. Growth and regulation of animal populations. Holt, Rinehart, and Winston. New York. $184 \mathrm{p}$.

Stobodkin, L. B. and A. L. Sanders.

1969. On the contribution of environmental predictability to species diversity. p. 82-95. In Diversity and stability in ecological systems. Brookhaven Symp. Biol. 22.

Soulé, M. and B. R. Stewart.

1970. The "niche-variation" hypothesis: a test and alternatives. Amer. Nat. 104: 85-97.

STICHEL, H.

1906. Parnassius. In (A. Seitz ed.) The Macrolepidoptera of the World. The Palearctic Butterflies. Alfred Kernen. Stuttgart. 1: 18-36.

1907. Parnassius. In (A. Seitz ed.) The Macrolepidoptera of the World. The American Rhopalocera. Alfred Kernen. Stuttgart. 5: $45-48$.

StraAtMan, $R$.

1962. Notes on certain Lepidoptera ovipositing on plants which are toxic to their larvae. J. Lepid. Soc. 16: 99-103.

Stride, G. O. and R. Straatman.

1962. The host plant relationship of an Australian swallowtail, Papilio aegeus, and its significance in the evolution of host selection. Linn. Soc. New South Wales 87: 69-78.

Thorsteinson, A. J.

1960. Host selection in phytophagous insects. A. Rev. Ent. 5: 193-218. 
Trimen, R. AND J. H. Bowker.

1889. South African Butterflies. Trubner and Co. London. 3: 191-254.

VANVALEN, L.

1965. Morphological variation and width of ecological niche. Amer. Nat. 99: 377-390.

VAURIE, C.

1957. Systematic notes on palearctic bird. No. 25. Motacillidae: the genus Motacilla. Amer. Mus. Novitates 1832: 1-16.

Wellington, W. G.

1968. Qualitative changes in populations in unstable environments. Canad. Ent. 96: 436-451.

Whittaker, R. H. and P. P. Feeny.

1971. Allelochemics: Chemical interactions between species. Science 171: 757-770.

Whittaker, R. H., S. A. Levin and R. B. Root.

1973. Niche, habitat and ecotope. Amer. Nat. 107: 321-338.

WhitTaker, R. H., R. B. Walker and A. P. KRUCKeberg.

1954. The ecology of serpentine soils. Ecol. 35:258-288.

Williams, E. E.

1969. The ecology of colonization as seen in the zoogeography of Analine lizards on small islands. Quant. Rev. Biol. 44: 345-384.

WILLIS, J. C.

1973. A dictionary of the flowering plants and ferns. 8th ed. Cambridge Univ. Press. Cambridge. 1245 p.

WiLlson, M. F.

1969. Avian niche size and morphological variation. Amer. Nat. 103: 531-542.

WILson, E. O.

1961. The nature of the taxon cycle in the Melanesian ant fauna. Amer. Natur. 95 : 169-193.

Woophouse, L. G. O.

1950. The butterfly fauna of Ceylon. 2nd ed. The Columbo Apothecaries Co. Ltd. Columbo. $230 \mathrm{p}$.

Wynter-Blyth, M. A.

1957. Butterflies of the Indian region. Bombay Nat. Hist. Soc., Bombay. 523 p.

Young, A. M.

1972. Community ecology of some tropical rain forest butterflies. Amp. Midl. Nat. $87(1)$ : 146-157. 

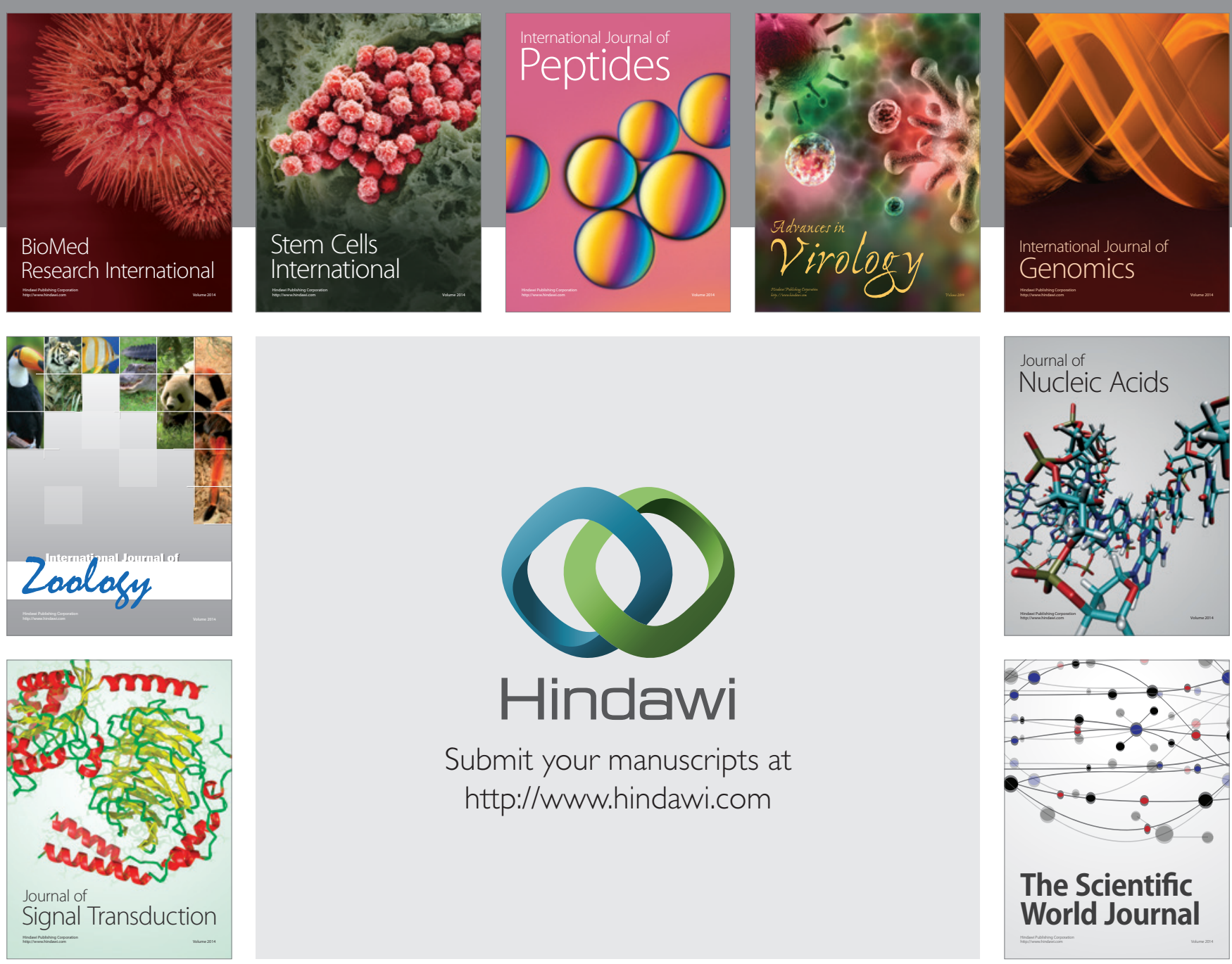

Submit your manuscripts at

http://www.hindawi.com
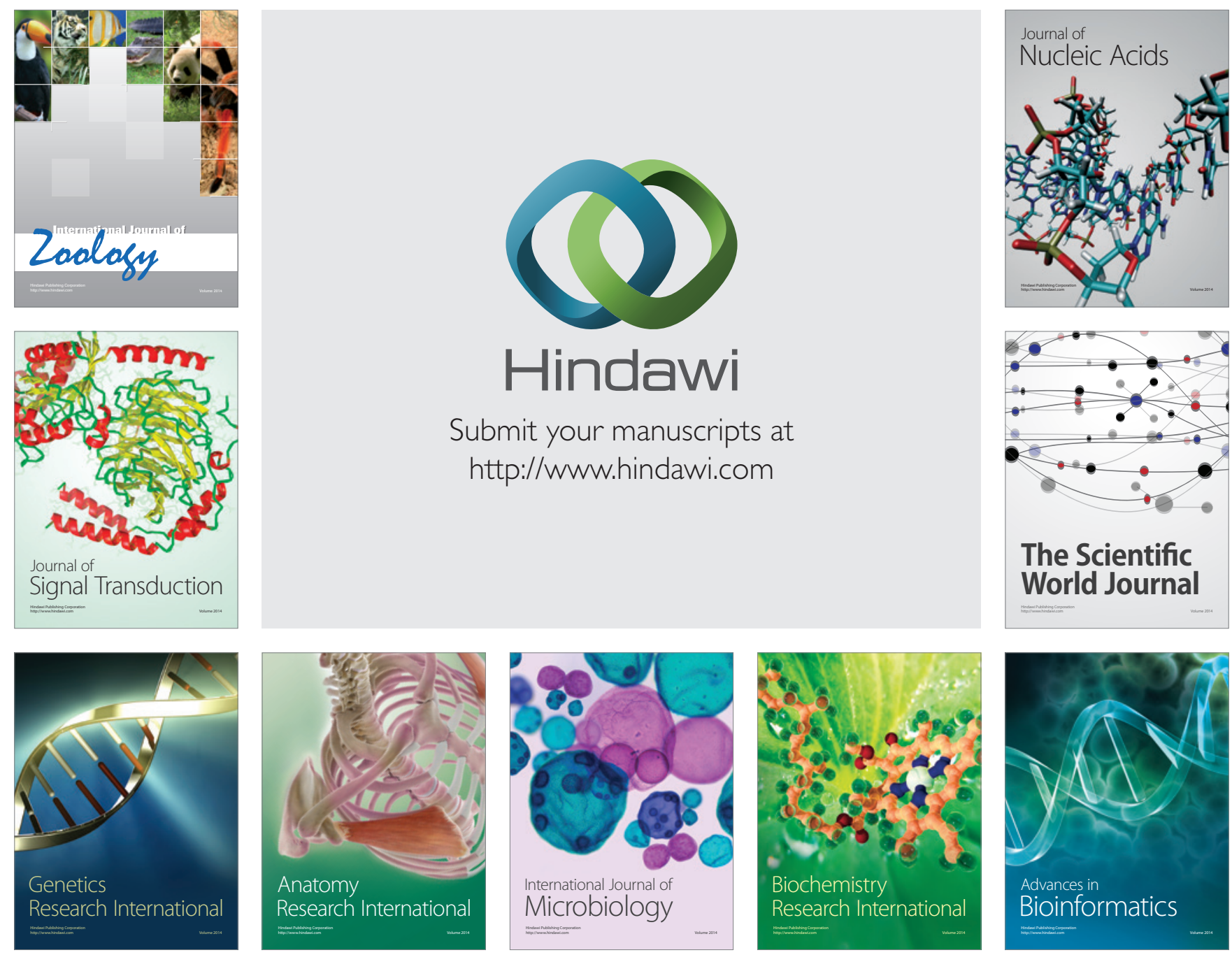

The Scientific World Journal
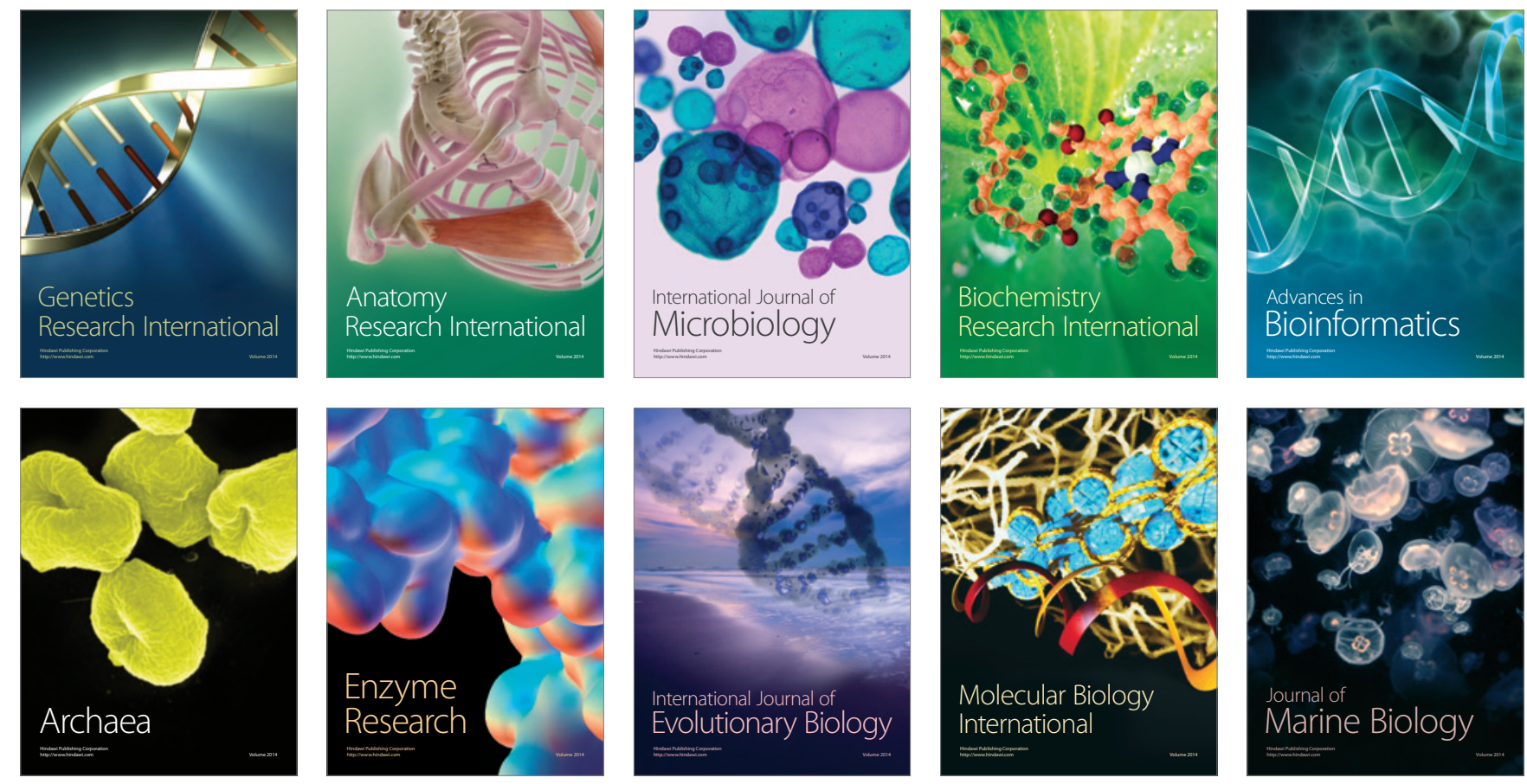